\title{
On the importance of paleoclimate modelling for improving predictions of future climate change
}

\author{
J. C. Hargreaves and J. D. Annan \\ Global Change Projection Research Program, Research Institute for Global Change, JAMSTEC, 3173-25 Showa-machi, \\ Kanazawa-ku, Yokohama City, Kanagawa, 236-0001, Japan
}

Received: 21 July 2009 - Published in Clim. Past Discuss.: 29 July 2009

Revised: 23 October 2009 - Accepted: 1 December 2009 - Published: 21 December 2009

\begin{abstract}
We use an ensemble of runs from the MIROC3.2 AGCM with slab-ocean to explore the extent to which midHolocene simulations are relevant to predictions of future climate change. The results are compared with similar analyses for the Last Glacial Maximum (LGM) and pre-industrial control climate. We suggest that the paleoclimate epochs can provide some independent validation of the models that is also relevant for future predictions. Considering the paleoclimate epochs, we find that the stronger global forcing and hence larger climate change at the LGM makes this likely to be the more powerful one for estimating the large-scale changes that are anticipated due to anthropogenic forcing. The phenomena in the mid-Holocene simulations which are most strongly correlated with future changes (i.e., the mid to high northern latitude land temperature and monsoon precipitation) do, however, coincide with areas where the LGM results are not correlated with future changes, and these are also areas where the paleodata indicate significant climate changes have occurred. Thus, these regions and phenomena for the mid-Holocene may be useful for model improvement and validation.
\end{abstract}

\section{Introduction}

Model predictions of long term climate change cannot be validated through repeated forecast/analysis cycles in the same manner as weather forecasts, as the necessary time scale is too long. Models are routinely evaluated in terms of how well they represent current climate, although this only appears to provide rather limited evidence for their future performance (Whetton et al., 2007; Abe et al., 2009). Researchers have, therefore, been motivated to look for times

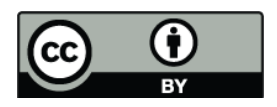

Correspondence to: J. C. Hargreaves (jules@jamstec.go.jp) in the past when the climate was rather different to today, because a model that does a good job of modelling paleoclimates may reasonably be considered preferable to one that does not. However, this hypothesis is so far largely untested. Similar processes do not necessarily govern all past and future climate changes, so it is arguable that what we really should seek are those climate changes in the past that are in some way analogous to or informative regarding the future changes we expect to see.

As observational evidence tends to become more sparse and uncertain at more distant times, much effort has been focussed on more recent paleo-climates such as the midHolocene (6 ka BP) and Last Glacial Maximum (LGM, $21 \mathrm{ka} \mathrm{BP}$ ). Model simulations of these epochs have formed the centrepiece of Paleoclimate Modelling Inter-comparison Projects PMIP and PMIP2 (Joussaume et al., 1999; Braconnot et al., 2007a). However, there is relatively little research directly addressing the extent to which these paleoclimate epochs are informative or the processes governing the climate changes analogous to those effecting future change. For example, one might question how essential it is to accurately simulate the response and climate feedbacks due to the huge ice sheets present over large parts of the Northern Hemisphere at the LGM, since for the modern climate and in coming decades, we expect at most small changes in the amount of terrestrial ice. However, at the LGM, there was also a significant decrease in the the forcing from greenhouse gases (primarily $\mathrm{CO}_{2}$ ) compared to present day levels, and we may expect that the response to this forcing involves similar processes to those relevant to future change.

Annan et al. (2005) and Hargreaves et al. (2007) investigated an ensemble of the MIROC3.2 AGCM (coupled to a slab ocean) in which parameters were constrained by observations of the current climate state. While such an approach can investigate the range of responses arising from parametric uncertainties, an acknowledged limitation is that the use of a single model precludes exploration of structural

Published by Copernicus Publications on behalf of the European Geosciences Union. 
limitations of the model. They found a reasonably strong correlation between the climate changes for the LGM and doubled $\mathrm{CO}_{2}$, especially away from the large Northern Hemisphere ice sheets. Using a simpler atmospheric model (but a three-dimensional ocean), Schneider von Deimling et al. (2006) obtained broadly comparable results. However, Crucifix (2006) examined results from 4 distinct AOGCMs and found no evidence of a relationship between the climate changes seen at the LGM and $2 \times \mathrm{CO}_{2}$ states, although with such a small ensemble, statistical significance would be hard to achieve. Thus, the results obtained here must be considered in the context of the single model that underlies the experiments. Since multi-model experiments are obviously outside our capabilities, we hope that our results will encourage other groups to attempt similar investigations.

In this paper we explore the climate changes for the midHolocene to see to what extent modelling that epoch may help improve forecasts of future climate, and compare our results to similar analysis of LGM simulations. Although paleoclimate studies are gaining in popularity, most comparison with data for GCMs is made against the present day climatology. Therefore, to further set this work in context we also compare the results to similar analyses for the preindustrial control simulation. The mid-Holocene might appear at first to be a rather weak analogue for future climate change since at this epoch there are no large changes in the net forcing or greenhouse gas levels. Moreover, the overall climate changes at the mid-Holocene are rather different in character compared to those expected to occur in the future (Mitchell, 1990). Thus, we do not expect the climate changes to be a close analogue in the sense of being directly applicable to future projections. Rather, we are looking for climate phenomena that respond to the same uncertain inputs, so that, as Mitchell (1990) proposes, analysis of paleoclimate changes might be useful for the estimation of model parameters that also control future changes. Paleodata from the mid-Holocene do indicate some significant changes which may be relevant to future climate change. The most prominent example is the evidence that the monsoon regions extended further northward than today, a result shown most dramatically by evidence for greening of parts of the present day Sahara desert (Jolly et al., 1998). Current predictions for the future changes of the monsoon under global change are highly uncertain, with disagreement in the models over the sign of the precipitation change (e.g. Fig. 10.9, Solomon et al., 2007). Therefore in this paper we analyse monsoon changes as well as zonal and global changes.

\section{Boundary conditions for mid-Holocene and LGM climate simulations}

The forcing for the mid-Holocene in the PMIP2 protocol (Braconnot et al., 2007a) consists of a small change to the $\mathrm{CH}_{4}$ concentration relative to the pre-industrial level (from
$760 \mathrm{ppm}$ to $650 \mathrm{ppm}$ ) and a change in the orbital forcing calculated from Berger (1978). The change to the orbital forcing affects the seasonal cycle and also changes the lengths of the seasons by up to 5 days (Joussaume and Braconnot, 1997). The use of the classical calendar for both experiments results in a mismatch between monthly results when compared to a true solar calendar. However, the analysis discusssed in this paper pertains to assessing correlations between variables over the ensemble, and we expect the effect of this calendar inaccuracy on our results to be small since it affects all ensemble members equally. The PMIP2 protocol for the LGM consists of a significant decrease in the levels of greenhouse gases compared to the modern climate, the inclusion of fixed massive ice sheets over the Northern Hemisphere and a small change in the orbital forcing (see Braconnot et al., 2007a for details). We also performed the PMIP2 pre-industrial control (CTRL) and a future climate experiment which has an increased carbon dioxide concentration but is otherwise identical to the pre-industrial.

\section{Method}

For our experiments we use a 36 member ensemble of runs of the MIROC3.2 AGCM with slab ocean, at T21 resolution. The ensemble generation method closely follows Annan et al. (2005), in which an ensemble Kalman filter was used for multivariate parameter estimation by tuning the model to various fields of modern climatological data, producing a 40 member ensemble. However, in this experiment we only allowed 13 model parameters to vary (selecting those which had been found to most strongly influence model results). We use a slab ocean model to reduce the equilibration time of the model, as is usual for such perturbed parameter ensemble experiments (e.g. Murphy et al., 2004). This requires the calculation of implied heat fluxes at each grid box (the so-called Q-flux field) to mimic the lateral transport of heat (Russell et al., 1985). Although in principle this flux field should integrate to zero for an equilibrium state, if no particular care is taken, the Q-flux field may have a large nonzero integral, indicating that the model is far from radiative balance under modern conditions. We found that in our previous work, there was a substantial radiative imbalance of around $10 \mathrm{Wm}^{-2}$ both for the ensemble members, and also for the unperturbed model when run at T21 resolution. Therefore, in this experiment, we imposed an additional constraint on the global and annual average of the Q-flux to reduce the radiative imbalance to around $2 \mathrm{Wm}^{-2}$, similar to or lower than the results of Collins et al. (2006). Further details of the ensemble are described in Yokohata et al. (2009). All the runs are at least 40 years long, with the last 20 years averaged to provide the results. The imposition of the Q-flux constraint resulted in an increase in the climate sensitivity of the ensemble, to $7.0 \pm 3.7^{\circ} \mathrm{C}$ ( 2 standard deviations). For the doubled $\mathrm{CO}_{2}$ experiment a number of the ensemble members 
with higher control temperature and high sensitivity became unstable once the global mean surface temperature exceeded $\sim 296 \mathrm{~K}$. According to the IPCC AR4, climate sensitivity is likely to lie in the range $2-4.5^{\circ} \mathrm{C}$ (IPCC 2007: summary for Policymakers, Solomon et al., 2007). In this experiment we are, therefore, exploring the climate behaviour for the unlikely higher values of climate sensitivity. Given the interest in the possible consequences of such high sensitivities, in order to obtain a stable ensemble which could reasonably be used for analysis, we performed another experiment using $\sqrt{2}$ times pre-industrial $\mathrm{CO}_{2}$ levels which reduces the equilibrium warming by $50 \%$ (for those models which do equilibrate). Apart from one ensemble member which crashed early on, and is also pathological for the LGM climate, all the other 39 ensemble members remained stable for a long run ( $>150$ years) with this forcing. Here we use the results from the larger $\sqrt{2} \times \mathrm{CO}_{2}$ ensemble but double the climate changes to ease comprehension of the values in the context of other literature, and refer hereafter to the result as $2 \times \mathrm{CO}_{2}$. For the LGM, one other ensemble member produced a state about $6{ }^{\circ} \mathrm{C}$ colder than the ensemble mean so this is considered to not represent a reasonable LGM and is excluded from the ensemble. Such abnormal cooling can be produced by a physically unrealistic cloud or sea-ice feedback and is a wellknown limitation of slab ocean models. The final 36 member ensemble is produced by further excluding two more ensemble members which produced similarly very cold states for a LGMGHG simulation (pre-industrial conditions with LGM greenhouse gases), that is not discussed in this paper, but is the subject of other analyses currently underway.

The underlying basis for our work is the expectation that our ensemble of models with varying parameters represents at least a large subset of our uncertainties concerning the physical processes controlling past and future climate change. We note that in support of this claim, the future projections for monsoon changes in this model ensemble (discussed in more detail later) include both increases and decreases in precipitation, similar to that exhibited by the IPCC ensemble of opportunity mentioned above. The first-order relationship between past and future data can be expressed as their covariances, which describes how the uncertainties in the future changes are related to uncertainties in past changes. If the covariance is low, then information about the past will not influence future predictions, but if the covariance is high, then this implies that information about the past will propagate into predictions. Therefore, we now explore our ensemble results to investigate where such relationships may exist. This approach is similar to the general principles underlying Observing System Simulation Experiments (Arnold Jr. and Dey, 1986), by which the value of observational data for prediction systems can be considered. However in this work here do not quantify the likely benefits, which also depends on the precision of the observational evidence that might be available.
Another important issue is that of the model inadequacy, that is the fact that the model cannot simulate reality perfectly for any set of parameter values. Moreover, different model ensembles may well exhibit somewhat different relationships between past and future climate, depending on their structure and parameterisations. The relationship is a property of the model and experimental details, rather than the climate system itself (which has one past and future trajectory). Therefore, while the existence of relationship between past and future climate (within a model ensemble) is a prerequisite in order for paleoclimate tuning to affect the future predictions, this may not be sufficient by itself to assure that the tuning will actually lead to improvements. We cannot address this question within this paper, but hope that the issues relating to this question can be further explored using ensembles of different models (e.g. Yokohata et al., 2009).

\section{Results}

\subsection{Analysis of annual averages on the global scale}

The difference between the control and mid-Holocene annually and globally averaged global $2 \mathrm{~m}$ temperatures (hereafter, T2) is rather small $\left(0.3 \pm 0.2^{\circ} \mathrm{C}\right.$ at 1 standard deviation $)$, reflecting the small change in the mean climate forcing. The correlation coefficient between the temperature change and climate sensivity is less than 0.1 . These results are not unexpected given the net forcing change is a small proportion of the seasonal and regional forcing. For the LGM simulations, MIROC shows a fairly strong correlation coefficient of 0.74 between the change in T2 from control to LGM, and climate sensitivity, consistent with but slightly higher than in previous work (Annan et al., 2005). These results are illustrated in Fig. 1. For reference, the level of statistical significance at $1 \%$ for a sample size of 36 , assuming independent samples, is 0.42 according to Student's t-test. While in our results we have used the $1 \%$ significance level as a guide to the significance of our results, it should be noted that in this work we have considered over 1000 different correlation coefficients, meaning that a number of false positives are to be expected in the results. A larger model ensemble, which is not at present computationally feasible, would improve the statistical confidence of our results.

For clarity and brevity, the three experiment-control differences for the $2 \times \mathrm{CO}_{2}, \mathrm{LGM}$, and mid-Holocene experiments are abbreviated to $\mathrm{D} 2 \times \mathrm{CO}_{2}, \mathrm{DLGM}$ and D6ka, respectively. Table 1 shows, for T2 and precipitation, the correlation coefficients between $\mathrm{D} 2 \times \mathrm{CO}_{2}$ and the other experiments. For $\mathrm{T} 2$, the control is significantly correlated with $\mathrm{D} 2 \times \mathrm{CO}_{2}$, but the DLGM shows a much stronger correlation. Note also that the control itself is also correlated with DLGM, indicating that the control and LGM may provide only partially independent constraints on modelled climate sensitivity. We illustrate this through regression models which predict the 


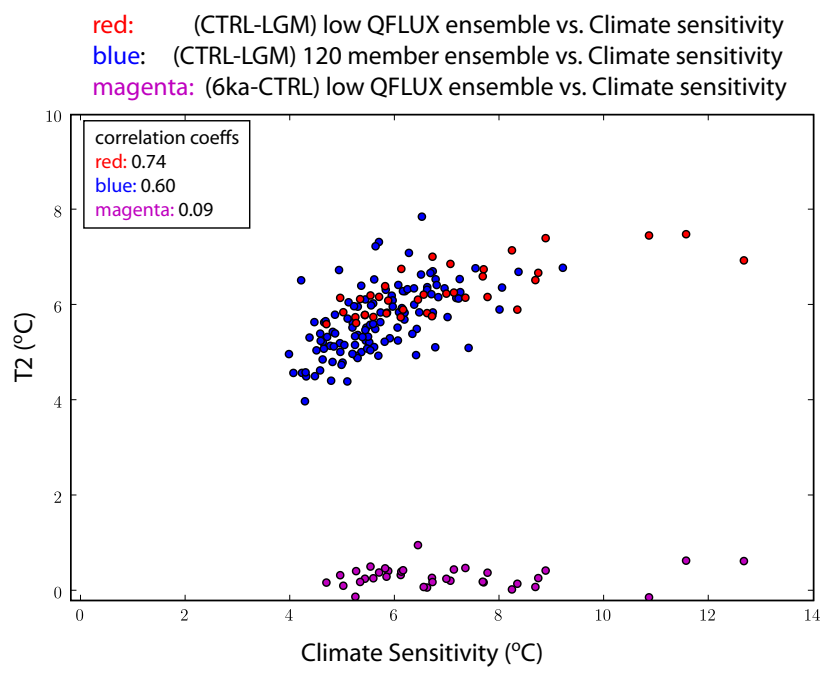

Fig. 1. Correlation between the temperature changes for $2 \times \mathrm{CO}_{2}$ and the two experiments, LGM and mid-Holocene. The blue dots show the results from previous work on the LGM, indicating that the results for the new low Q-flux ensemble are consistent, although of slightly higher sensitivity. The contrast between the strong signal for the LGM and very small global change for the mid-Holocene is clear.

global $\mathrm{D} 2 \times \mathrm{CO}_{2}$ temperature change using the DLGM and control temperatures (singly or jointly) as predictors. The control value alone explains $21 \%$ of the total variance, with the LGM explaining 55\% and both control and LGM together combining to explain $61 \%$.

For D $2 \times \mathrm{CO}_{2}$, there is an extremely high correlation between temperature and precipitation, so it is not surprising to also see significant correlation coefficients for the correlation of control and DLGM temperatures with precipitation for $\mathrm{D} 2 \times \mathrm{CO}_{2}$. Although the correlations indicate that a higher control temperature leads to increased climate sensitivity, and increased global precipitation change for $\mathrm{D} 2 \times \mathrm{CO}_{2}$, higher control precipitation leads to a smaller precipitation change for increased $\mathrm{CO}_{2}$. In contrast, for the LGM, the global precipitation changes are negative, and the larger the change in precipitation the greater the precipitation change for increased $\mathrm{CO}_{2}$. The negligible correlation between the control and DLGM precipitation suggests that these aspects of the LGM and control climates may be determined by (and therefore useful for constraining) different, independent processes in the model, and thus the information from both epochs may combine effectively. A similar regression analysis to the previous paragraph reveals that the control and DLGM results each explain almost $40 \%$ of the total variance of the $\mathrm{D} 2 \times \mathrm{CO}_{2}$ precipitation change, and in combination they explain $75 \%$ of the total variance. Again, the mid-Holocene makes a negligible contribution.
Table 1. Correlation between the global temperature and precipitation for the various experiments.

\begin{tabular}{lcccccccc}
\hline & \multicolumn{2}{c}{$\mathrm{D} 2 \times \mathrm{CO}_{2}$} & \multicolumn{2}{c}{$\mathrm{CTRL}$} & \multicolumn{2}{c}{$\mathrm{D} 6 \mathrm{ka}$} & \multicolumn{2}{c}{$\mathrm{DLGM}$} \\
& $\mathrm{T} 2$ & $\mathrm{ppt}$ & $\mathrm{T} 2$ & $\mathrm{ppt}$ & $\mathrm{T} 2$ & $\mathrm{ppt}$ & $\mathrm{T} 2$ & $\mathrm{ppt}$ \\
\hline $\mathrm{D} 2 \times \mathrm{CO}_{2} \mathrm{~T} 2$ & $\mathrm{X}$ & 0.98 & 0.45 & -0.71 & 0.09 & 0.12 & -0.74 & -0.54 \\
$\mathrm{D} 2 \times \mathrm{CO}_{2}$ ppt & - & $\mathrm{X}$ & 0.51 & -0.63 & 0.09 & 0.14 & -0.75 & -0.62 \\
$\mathrm{CTRL} \mathrm{T} 2$ & - & - & $\mathrm{X}$ & - & - & - & -0.30 & - \\
CTRL ppt & - & - & - & $\mathrm{X}$ & - & - & - & 0.04 \\
\hline
\end{tabular}

\subsection{Analysis of annual averages on the zonal scale}

One of the potential difficulties of using paleo-climate data to validate climate models is the mismatch in spatial scales between the GCMs, which are most reliable at the largest scales, and less so at smaller scales, versus paleoclimate data, which is generally highly local in nature. So, while the global calculations presented above indicate that there are links between the processes effecting climate changes at the LGM and $2 \times \mathrm{CO}_{2}$ climates, they do not shed any light on which regions may be effectively used to validate and improve the modelled predictions of future climate change. In addition, the changes in climate at the mid-Holocene, being caused by changes in the patterns of seasonal forcing, are expected to be far greater on zonal to regional scales than at the global average. The albedo forcing due to ice sheets at the LGM is also strongly linked to latitude. Thus we consider the relationship in the ensemble between the zonally averaged variables for D2 $\times \mathrm{CO}_{2}$, DLGM, D6ka, CTRL and the global scale changes for $2 \times \mathrm{CO}_{2}$. The mid-Holocene results provide a very small contribution, explaining less than $1 \%$ of the variance. The zonally averaged annual average temperatures for CTRL, D2 $\times \mathrm{CO}_{2}$, D6ka and DLGM are shown in Fig. 2. The heavier lines are the ensemble mean, whereas the lighter weight lines show the one standard deviation widths of the ensembles. The results from the correlation analysis are shown in Fig. 3. The red lines show the correlation of zonal and global temperature, and the blue show the correlation of zonal and global precipitation. As paleoclimate data for land and ocean is often analysed and synthesised independently, the correlation analysis is done for the land and ocean separately (solid and dashed lines, respectively). As shown in Fig. 3a, for $\mathrm{D} 2 \times \mathrm{CO}_{2}$ the temperature is strongly correlated with climate sensitivity over all latitudes. For precipitation, although the correlation is significant for most latitudes, it is mostly not as strongly correlated with global precipitation change, particularly over the land. The CTRL (Fig. 3b) temperatures are most strongly correlated with climate sensitivity over the land in the Northern Hemisphere, while the negative correlation for precipitation, aluded to above, arises from the low to mid-latitude ocean and the land around $40^{\circ}$ north and south. 

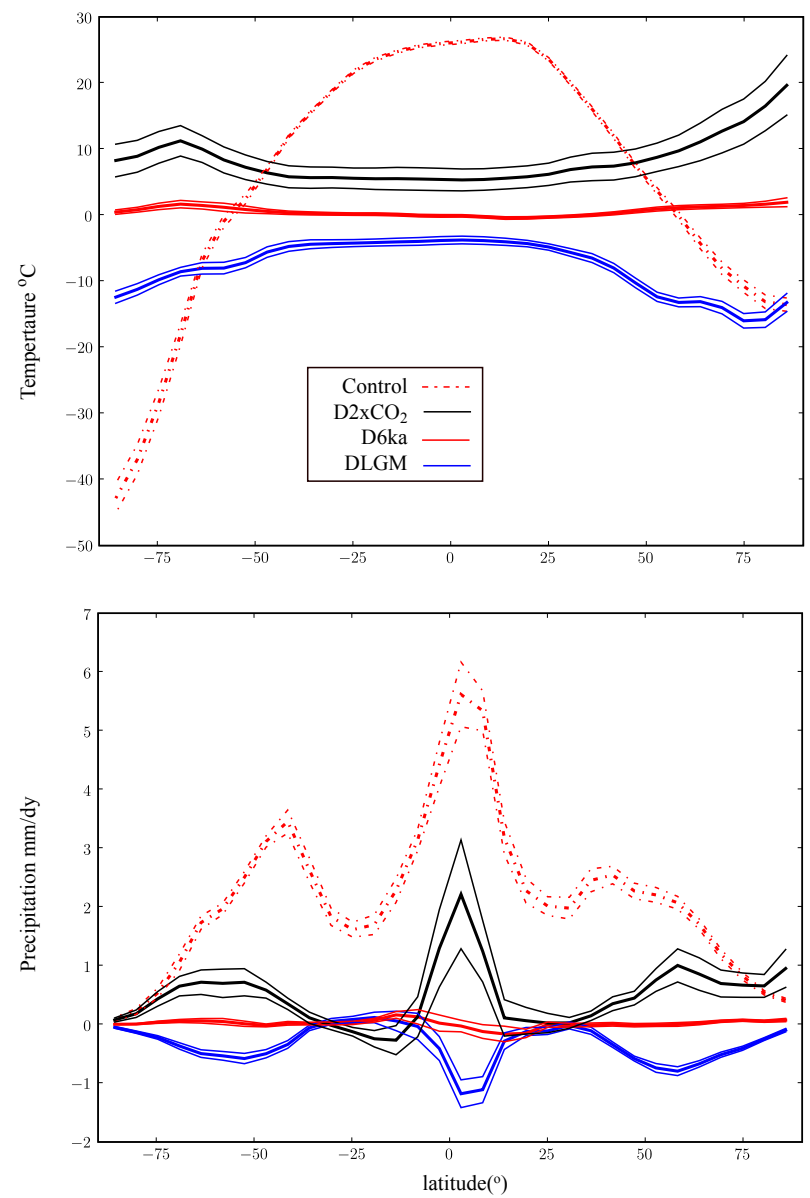

Fig. 2. Top: annually averaged temperature for the control climate, and the differences between the control and the simulated climates. The thinner lines show the 1 standard deviation ranges of the ensemble. Bottom: the same as the top plot, but for precipitation.

For D6ka (Fig. 3c) the correlation coefficients are mostly below the level of the noise, except for part of the Northern Hemisphere where the correlation is reasonably strong over the land in particular. Interestingly, this is the same latitude range for which the correlation coefficient for DLGM (Fig. 3d) temperature is rather weak, due to the existance of the large ice sheets (which was previously discussed in Hargreaves et al., 2007). In addition, for DLGM, as we noted in previous work (Hargreaves et al., 2007), although the correlation for temperature is generally very strong, small biases in the control sea-ice extent may strongly influence the temperature in the sea-ice region for increasing $\mathrm{CO}_{2}$, leading to no significant correlation for temperature in the sea-ice regions for DLGM. The situation for precipitation is, however, reversed with the correlation coefficient being rather strong for DLGM over the ocean from $40-70^{\circ} \mathrm{S}$.

From these results it would appear that the best data to use to improve the model predictions would be the temperatures in the tropics and very high latitudes along with precipita- tion in the southern ocean at the LGM, the mid-to-high latitude temperatures for the Northern Hemisphere at the midHolocene and the whole of the Northern Hemisphere temperatures and tropical precipitation for the pre-industrial climate. Given the very high correlation between the global temperature and precipitation for $\mathrm{D} 2 \times \mathrm{CO}_{2}$, the correlations for zonal temperature with global precipitation (not shown) look almost identical to the red lines in Fig. 3, and indicates that improving the temperature should also result in improved precipitation.

Correctly predicting globally averaged climate change, while still an important achievement scientifically, may not be as useful as knowing what the climate change will be in a particular region. In order to consider future changes on a somewhat smaller scale, Fig. 4 shows the correlation of the zonally averaged $\mathrm{D} 2 \times \mathrm{CO}_{2}$ with CTRL, D6ka and DLGM. For temperature, the curves look rather similar to those in Fig. 3. This comes as no surprise, given the strong zonal-global correlation of temperature at $\mathrm{D} 2 \times \mathrm{CO}_{2}$ shown in Fig. 3a. For precipitation, the results are, however, somewhat different to those in Fig. 3. The clearest correlation is the southern ocean region for DLGM. Apart from this, the correlation coefficient rises above the nominal noise level at various latitudes for all three experiments, mostly in the tropics. The correlation between zonal temperature for the experiments and zonal precipitation for $\mathrm{D} 2 \times \mathrm{CO}_{2}$ is not shown, but is similar in shape to what would result from the multiplication of the blue lines in Fig. 3a with the red lines in Fig. 4. In other words, the correlation tends to decrease in significance in those regions where the blue lines in Fig. 3a lie within the magenta band. So, for improving climate change prediction on the zonal scale the temperature may be similarly constrained on the global and regional scales, with the LGM being useful for the tropics and the high latitudes, and the control and mid-Holocene contributing in the northern hemisphere, while for precipitation all three experiments may provide some useful information, but none is particularly dominant.

Since there is considerable overlap with the results for the control with those for DLGM and D6ka, one may wonder if all we really need in order to build better models is to better fit them better to the modern climate. Figure 5 investigates this question for MIROC. It shows the correlation of DLGM and D6ka with CTRL for temperature. For D6ka, there is no significant correlation in the land over the Northern Hemisphere region where the significant correlation is found in Fig. 4b. Similarly, for DLGM the correlation is weak for the ocean and only marginally significant for small regions in the tropics. These results indicate that the paleo-climate experiments may be exercising different aspects relevant for climate change, than the control experiment. This suggests that improving the modelling of the paleoclimates, over and above the present day climate, can be expected to further improve future predictions. 

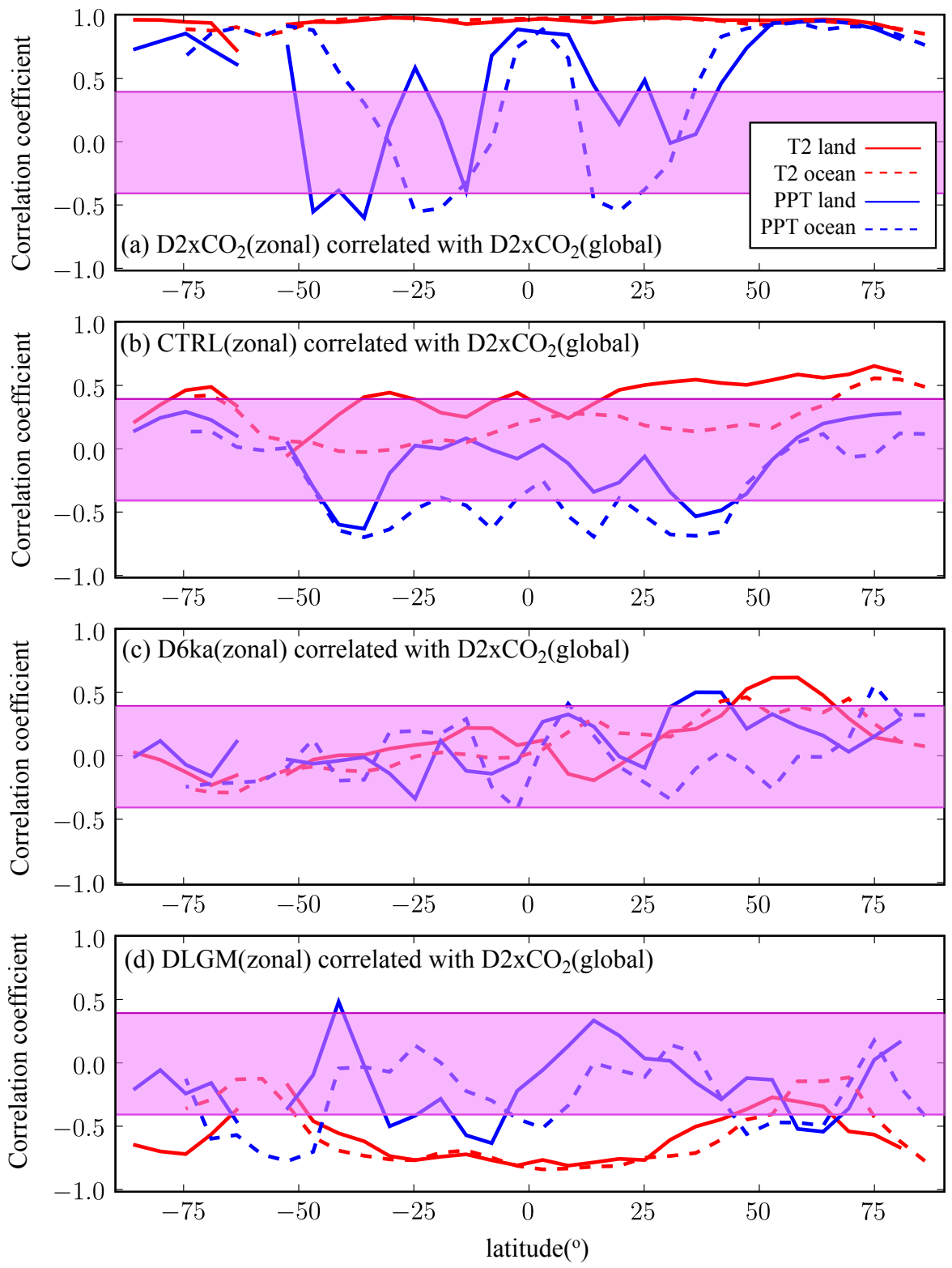

Fig. 3. Correlation of the annually averaged global changes for the $2 \times \mathrm{CO}_{2}$ experiment with the annually averaged zonal changes for all the experiments, for both precipitation and $2 \mathrm{~m}$ temperature. The results are split into separate results for land and ocean. The magenta band shows the region which does not achieve significance at the $99 \%$ level.

\subsection{Analysis of seasonal averages}

Tsushima and Manabe (2001) suggested that the global response of the climate system to seasonal variation may be analagous to the global changes that occur under global warming. Using this assumption, they argued that since the cloud feedback effect was small for the annual global temperature variation, it could also be small for the case of anthropogenic global warming. In our ensemble, however, we do not find a significant correlation between the present-day global seasonal temperature signal and climate sensitivity.
Analysis on the zonal scale presents a more interesting picture. The dashed line in the bottom plot of Fig. 6 indicates the zonal variation of the correlation between the control seasonal signal (JJA-DJF temperature over land), and climate sensitivity for our model ensemble. The correlation is stronger around $25-30^{\circ} \mathrm{N}, 70^{\circ} \mathrm{N}, 70^{\circ} \mathrm{S}$ and $25-30^{\circ} \mathrm{S}$. In addition these same parts of the globe also show the strongest correlation for $\mathrm{D} 2 \times \mathrm{CO}_{2}$ with climate sensitivity. It would, therefore, appear that the MIROC results are similar in character to those of HadSM3 in Knutti et al. (2006), who also found that many Northern Hemisphere extratropical land 

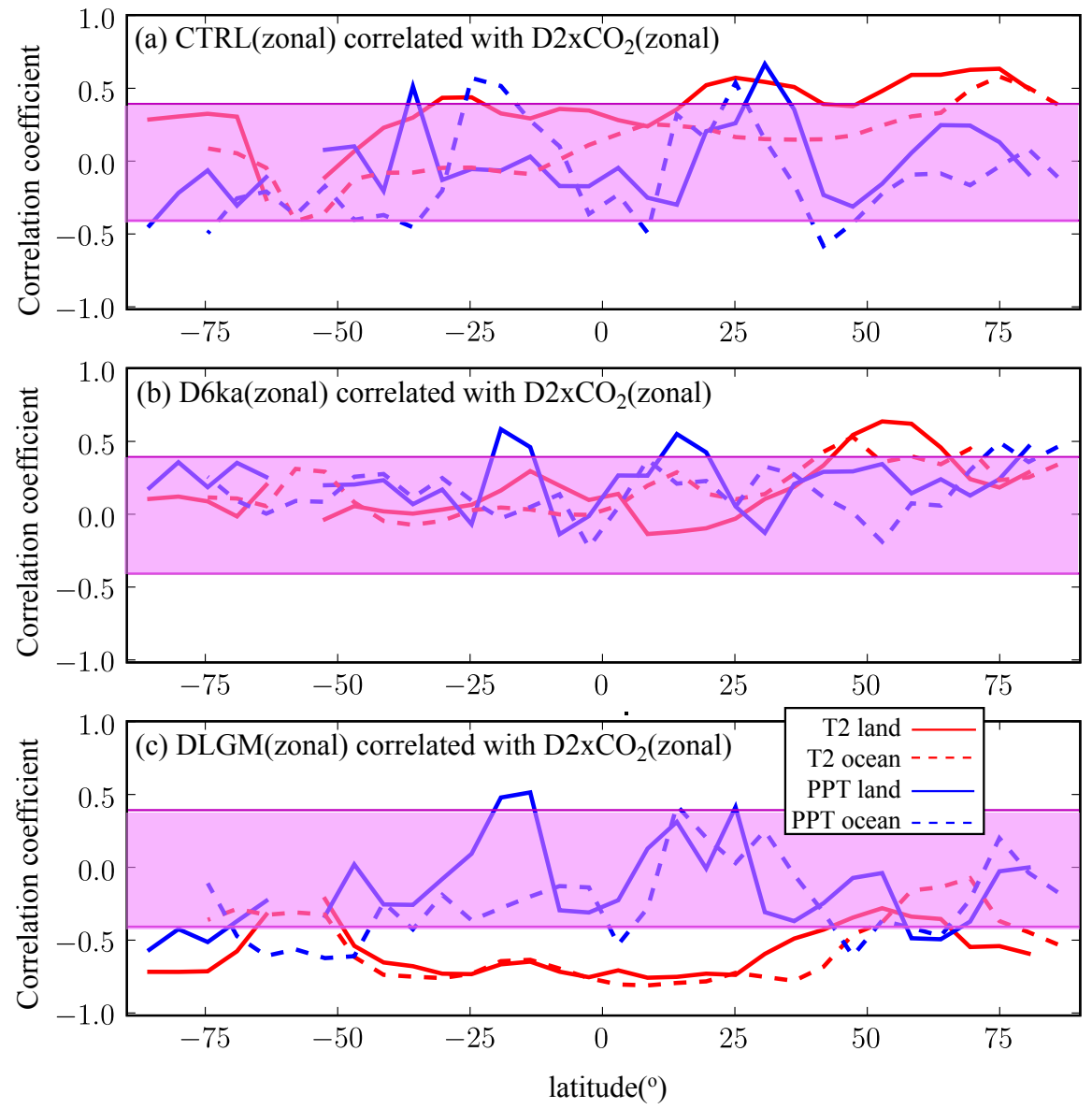

Fig. 4. Correlation of the annually averaged zonal changes for the $2 \times \mathrm{CO}_{2}$ experiment with the annually averaged zonal changes for all the experiments, for both precipitation and $2 \mathrm{~m}$ temperature. The results are split into separate results for land and ocean. The magenta band shows the region which does not achieve significance at the $99 \%$ level.

regions showed a positive correlation between climate sensitivity and the magnitude of the seasonal signal. Based on these results it would seem likely that although the seasonal signal alone could not be used to precisely estimate climate sensitivity, improving the present-day seasonal signal in the models may help improve the prediction of future changes.

Since the forcings for the mid-Holocene climate largely consist of changes in the seasonal forcing we might also hope that getting the correct seasonal response in the model for the mid-Holocene will help improve our climate model, and its ability to predict future change. However, we find little evidence to support this. Figure 6 shows that changes in seasonal cycle for DLGM of a similar magnitude (and opposite sign) to the changes for the increased $\mathrm{CO}_{2}$ climate, whereas those for D6ka are much smaller. The correlation between DLGM and climate sensitivity is quite high over the high latitude bands and moderate in the mid-latitudes. For D6ka, in contrast, the correlation coefficients mostly do not rise above the level of the sampling noise. These results suggest that the seasonal cycle at the LGM may actually be as useful for improving predictions as that at the present-day, and more useful than the mid-Holocene. Of course in order to take advantage of this relationship, we would need paleodata that is informative of the seasonal cycle at those times, and decomposing the seasonal climate signal from paleo-data is not generally currently feasible, although this result may become of more practical importance as proxies are better understood and modelled.

\subsection{Monsoon regions}

As mentioned in the Introduction, one of the reasons for studying the mid-Holocene epoch is the evidence for increased monsoon precipitation, and for vegetation further north in the African monsoon region, compared to the present day. Given this regional-scale evidence, we examine the correlations of the model responses to changes in forcing in these regions. We take our definition of the monsoon regions from Braconnot et al. (2007a) and Ohgaito and AbeOuchi (2007). For the Asian monsoon region, Braconnot 

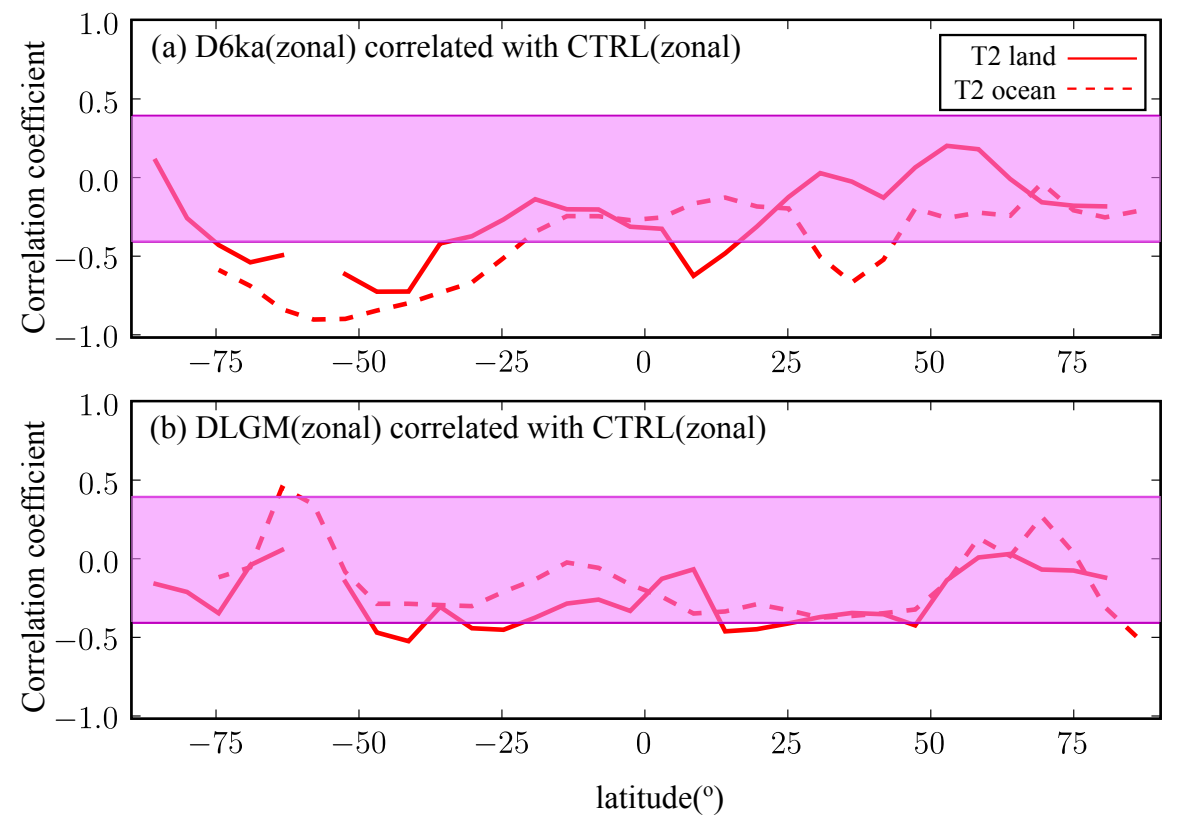

Fig. 5. Correlation of the annually averaged zonal temperatures for the CTRL experiment with the annually averaged zonal temperaure changes for the LGM and mid-Holocene. The results are split into separate results for land and ocean. The magenta band shows the region which does not achieve significance at the $99 \%$ level.

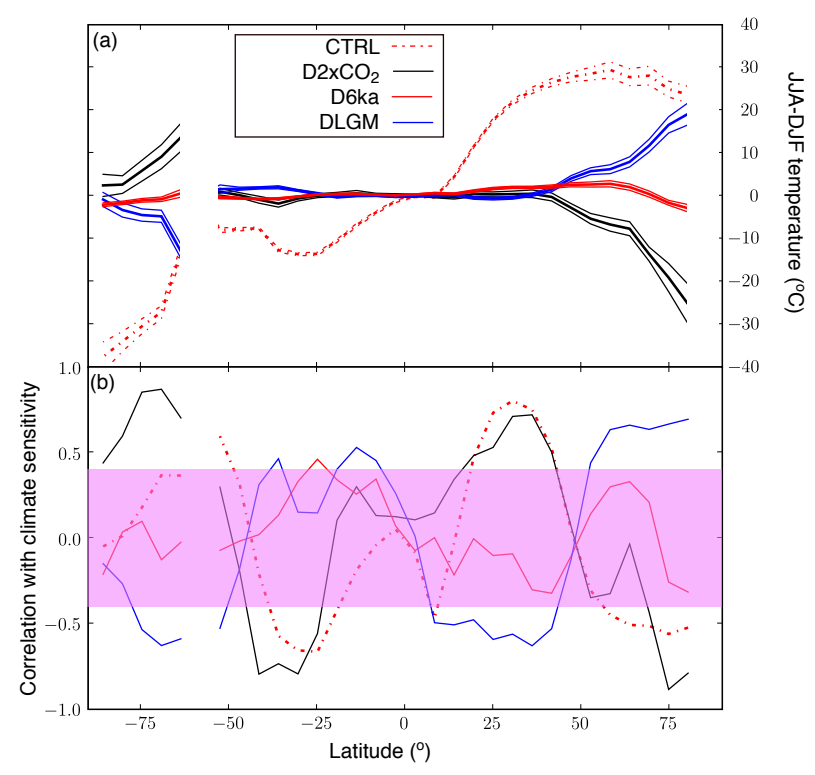

Fig. 6. (a) Seasonal (JJA-DJF) zonally averaged temperature difference over land for the control climate (dot-dashed line) and the differences between the control and the simulated climates (solid lines). The thinner lines show the 1 standard deviation ranges of the ensemble. (b) Ensemble correlation of the seasonal change with climate sensitivity. et al. use a region focussed around northern India (70$100^{\circ} \mathrm{E}, 20-40^{\circ} \mathrm{N}$ ), while Ohgaito and Abe-Ouchi use a region which extends further east as far as Japan $\left(70-140^{\circ} \mathrm{E}\right.$, $\left.22-40^{\circ} \mathrm{N}\right)$. We compare results from both these regions. We also analysed the West African monsoon region $\left(20^{\circ} \mathrm{W}-\right.$ $\left.30^{\circ} \mathrm{E}, 10^{\circ} \mathrm{N}-25^{\circ} \mathrm{N}\right)$.

Data on land for the mid-Holocene and LGM are typically taken from remnants of biological material, so may contain information on a mixture of seasonal temperature, precipitation and other environmental factors. In the next few years we expect researchers to move towards utilising more of this information, for example, by directly modelling the climate proxies. Therefore we present results for the monsoon climate on a monthly basis. The monthly mean temperature results for the different regions are shown in Fig. 7. Figure 7c, $\mathrm{d}$ show the correlations of monthly temperatures for CTRL, DLGM and D6ka with those for D2 $\times \mathrm{CO}_{2}$. The results are similar for both regions, with the correlation being strongest for DLGM and moderate for CTRL, while there is no significant correlation for D6ka. In this case we do also find significant correlation between the CTRL and DLGM temperatures, suggesting that these data do not test independent aspects of the model. Figure 7e, f show the correlation of the CTRL, DLGM and D6ka temperatures with precipitation for D $2 \times \mathrm{CO}_{2}$. Here the results are less significant although there are a small number of months where there is some significant correlation for DLGM in the larger Asian monsoon region and also for DLGM and CTRL in West Africa. Figure 8 

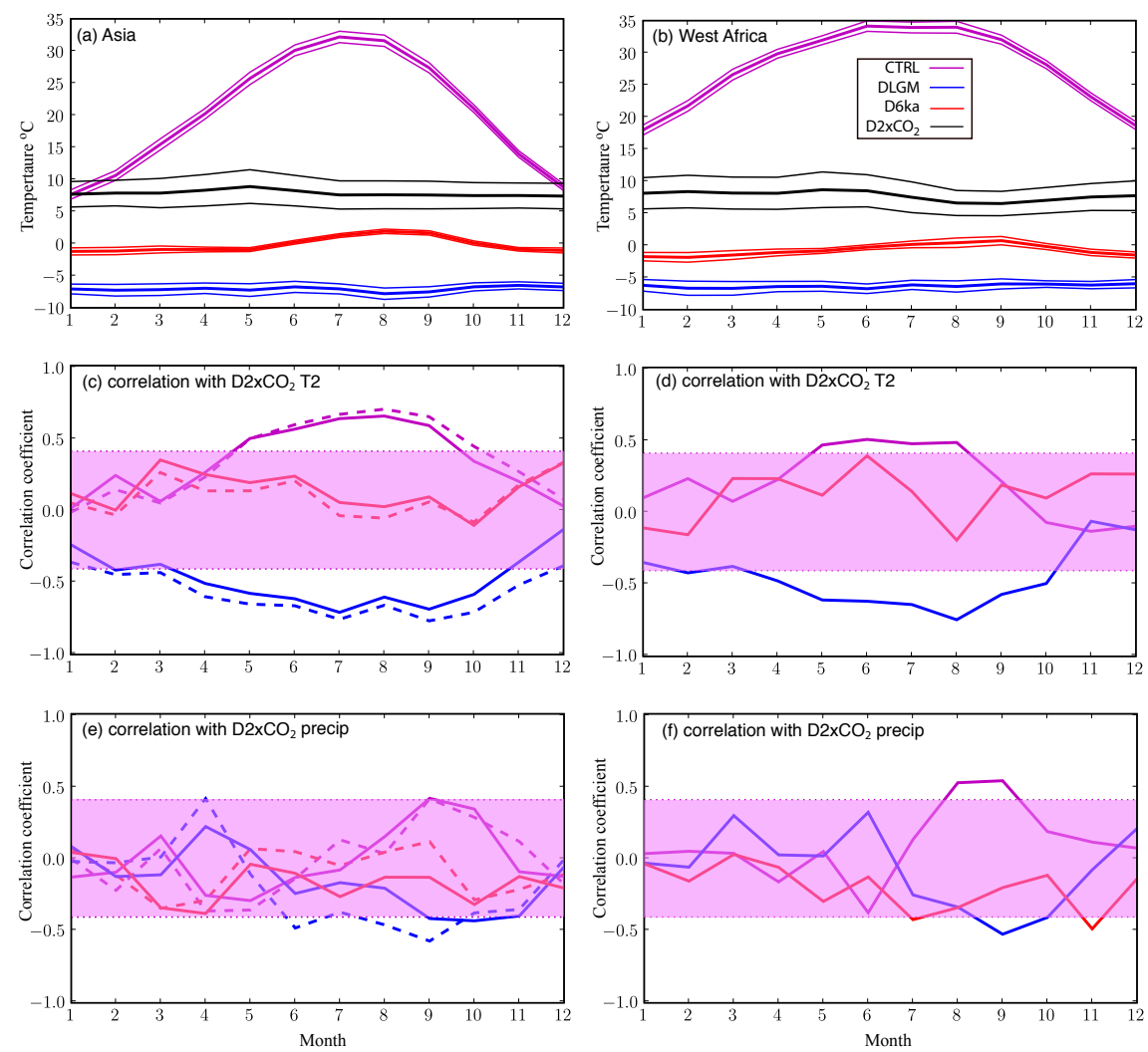

Fig. 7. Correlation of monthly $2 \mathrm{~m}$ temperature results for the monsoon region. Left plots, Asia; solid lines, Braconnot et al. (2007a) region; dashed lines: Ohgaito and Abe-Ouchi (2007) region. Right plots, West Africa, Braconnot et al. (2007a). (a, b) Temperatures for CTRL, DLGM, D6ka and D2 $\times \mathrm{CO}_{2}$. (c, d) Correlation of monthly temperature for CTRL, DLGM, D6ka with monthly temperature for D2 $\times$ CO 2 . (e, f) Correlation of monthly temperature for CTRL, DLGM, D6ka with monthly precipitation for D2 $\times \mathrm{CO}_{2}$.

shows the results for the precipitation for CTRL, DLGM and D6ka. Figure 8a, b show the precipitation for CTRL, DLGM, D6ka and $\mathrm{D} 2 \times \mathrm{CO}_{2}$ for the two regions. It is notable here that the changes are rather large for $\mathrm{D} 2 \times \mathrm{CO}_{2}$, DLGM and D6ka when compared to the base annual cycle of the control run. All experiments, but particularly $\mathrm{D} 2 \times \mathrm{CO}_{2}$ have a large ensemble spread from May to October, indicating a high degree of uncertainty in the ensemble predictions. Figure 8 b,c show the results for the correlations with $\mathrm{D} 2 \times \mathrm{CO}_{2}$ precipitation. For Asia, only D6ka shows any significant correlation with precipitation at $\mathrm{D} 2 \times \mathrm{CO}_{2}$, while for Africa D6ka has signficant correlation coefficients for 7 months of the year, and the CTRL for 4 months. The correlation of the CTRL with D6ka (not shown) is only significant for the month of November.

To summarise the results for the monsoon regions, improving temperatures in the monsoon regions for LGM and CTRL simulations would be expected to improve future predictions of temperature. For precipitation the evidence is much weaker, but the most notable feature is that, for the monsoon regions, the results for the mid-Holocene are at least as strong as those for the other epochs.

\section{Discussion}

For MIROC, there is evidence that improving both the preindustrial and LGM temperatures and precipitation should influence both the estimates of climate sensitivity and global precipitation change. For estimating future changes on the zonal scale, evidence from the pre-industrial, LGM and mid-Holocene should all prove useful. Moving to the regional scale of the monsoon, the LGM and pre-industrial climates are clearly the most useful for improving future temperatures. For the all-important prediction of the monsoon rainfall change, the evidence is less strong, but in our results, the mid-Holocene precipitation, and to a lesser extent the pre-industrial temperature and precipitation would seem to be most useful.

Adding to the potential value of the mid-Holocene climate is the fact that in the regions for which we found the most significant results in our model-model correlations, there is also clear evidence of changes in climate from the mid-Holocene data. For the mid to high latitude land in the Northern Hemisphere (Sects. 4.1 and 4.2), there is evidence from the proxy data which may be used for model validation. In particular, 

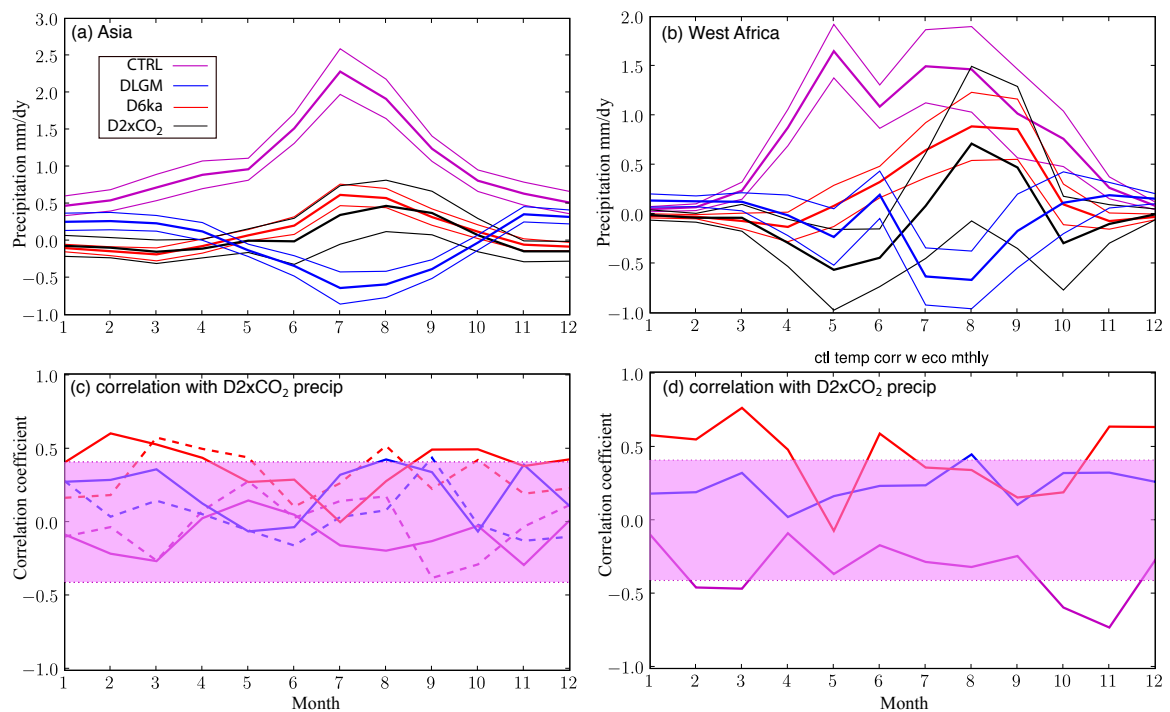

Fig. 8. Correlation of monthly precipitation results for the monsoon region. Left plots, Asia; solid lines, Braconnot et al. (2007a) region; dashed lines: Ohgaito and Abe-Ouchi (2007) region. Right plots, West Africa, Braconnot et al. (2007a). (a, b) Precipitation for CTRL, DLGM, D6ka and D2 $\times \mathrm{CO}_{2}$. (c, d) Correlation of monthly precipitation for CTRL, DLGM, D6ka with monthly precipitation for D2 $\times \mathrm{CO}_{2}$.

there is evidence for warmer climates compared to present in the northern latitudes of Eurasia (Tarasov et al., 1999; Bigelow et al., 2003).

One of the clearest features of the mid-Holocene climate found in proxy records is the change in vegetation type in the Sahara north of the present-day monsoon region compared to the present day. To date most climate models have not managed to reproduce this feature (Braconnot et al., 2007a and references therein). For the mid-Holocene, while there is a general increase in the monsoon precipitation and a northward shift in the ITCZ over Africa (Braconnot et al., 2007b), very few models (and none of our ensemble members) have produced enough of a climate change to induce significant vegetation changes in the Sahara (Braconnot et al., 2007a). It is of some concern that there should be such strong evidence for bias across so many models, indicating that the models do not properly represent the processes governing the mid-Holocene. If that is the case, then our finding correlations between the mid-Holocene and the future climate in the model-space may not translate directly for the real world, since the missing processes may overwhelm our results. On the other-hand, the fact that there is such a clear signal in the paleo-data gives us some good evidence in the past with which to validate and improve the model. Given the shortage of data for validating climate changes, and the fact that we do get a significant correlation between mid-Holocene and increased $\mathrm{CO}_{2}$ climates actually suggests that further improving the simulation of the mid-Holocene climate would be a suitable focus for those wishing to improve predictions of the future.
In this context is worth noting that modern GCMs do not agree on the sign of the change for future precipitation in the monsoon regions (Meehl et al., 2007), whereas those that have been run for PMIP2 do all agree on an increase for the mid-Holocene compared to present (Braconnot et al., 2007a). Despite only using a single model in our experiments, our results are consistent with this. As Fig. 8a, b imply, the precipitation changes in the monson season are all positive for the D6ka experiment, while for the $\mathrm{D} 2 \times \mathrm{CO}_{2}$ experiment we see both increases and decreases among the ensemble members. For the annual mean rainfall in the three monsoon regions, the precipitation change is negative for $40 \%$ of the $\mathrm{D} 2 \times \mathrm{CO}_{2}$ members but negative for only $1 \%$ of the D6ka members.

For practical reasons, an in depth analysis of the processes and feedbacks governing the different climate changes studied here is outside the scope of this paper, and is left as a subject for future studies. We are also aware that our study focusses on only one model, and that the results are not necessarily directly tranferrable to other models, or even future development of MIROC. For example, the (unperturbed) T42 version of MIROC3.2 does not suffer from the large radiative imbalance that we found with the lower resolution T21 version (and discussed in Sect. 3), but due to computational constraints we were limited to using the latter. As has previously been noted, correlations across multiple models tend to be weaker than in individual model ensembles, as there are many more differences between different models than can be represented by changing a limited number of parameters in one model (Crucifix, 2006). In addition, the MIROC3.2 slab-ocean model omits some potentially important feedbacks, such as the effect of ocean dynamics and 
vegetation response. While previous work with MIROC3.2 has indicated that the influence of the ocean dynamics on the monsoon is not of first order importance (Ohgaito and Abe-Ouchi, 2007), recent work integrating a dynamic vegetation model (LPJ) into the standard version of MIROC3.2 has shown that for increased $\mathrm{CO}_{2}$, the dynamic vegetation amplifies the increase in precipitation in the monsoon regions (O'ishi and Abe-Ouchi, 2009). It is, therefore, possible that the inclusion of dynamic vegetation could bring the models closer to modelling the green Sahara at the mid-Holocene. Therefore, it would be helpful if other similar analyses could be undertaken with different models incorporating different feedbacks.

\section{Conclusions}

On the whole we find that the LGM, with its relatively large negative change in $\mathrm{CO}_{2}$ forcing, is more likely to be useful for constraining future climate change, despite the noise in the correlations introduced by the responses to large ice sheet changes which do not seem relevant to future climate change. For large-scale variables such as climate sensitivity, and the seasonal signal on zonal scales, analysing the behaviour of the mid-Holocene would seem to be less helpful. The one exception to this is the northern high latitude land, where at the LGM the large ice sheets causes the relation to the increased $\mathrm{CO}_{2}$ climate change to be weak, whereas the changes in mid-Holocene temperatures over land are, in fact, moderately well correlated with both climate sensitivity and the zonal changes for increased $\mathrm{CO}_{2}$. On the more regional scale of the African and Asian monsoons, the mid-Holocene shows interesting results for the precipitation changes, although the LGM is again more relevant for temperature.

The case for continuing modelling of the mid-Holocene is supported by the availability of observational evidence which indicates climatic conditions significantly different from present in both these regions, which may be used to validate the models. There is evidence for a warmer climate compared to present in the northern latitudes of Eurasia from proxy data. It is also well known that the modelled monsoon changes at the mid-Holocene are insufficiently dramatic: there should be more rain further north, particularly in Africa (Braconnot et al., 2007a). While the caveats relating to model inadequacy mentioned in Sect. 3 should be kept in mind, because the effect of increased $\mathrm{CO}_{2}$ on monsoon precipitation is highly uncertain, the mid-Holocene should not be ignored.

Acknowledgements. The authors would like to thank A. Abe-Ouchi for encouragement and discussions which led to the development of this work, R. Ohgaito for crucial assistance with MIRCO3.2, and the two referees, M. Crucifix and A. Ganopolski for their helpful suggestions. This work was supported by Innovative Program of Climate Change Projection for the 21st Century of the Ministry of
Education, Culture, Sports, Science and Technology (MEXT), and by the Global Environment Research Fund (S-5-1) of the Ministry of the Environment, Japan.

Edited by: V. Masson-Delmotte

\section{References}

Abe, M., Shiogama, H., Hargreaves, J., Annan, J., Nozawa, T., and Emori, S.: Correlation between Inter-Model Similarities in Spatial Pattern for Present and Projected Future Mean Climate, SOLA, 5, 133-136, 2009.

Annan, J. D., Hargreaves, J. C., Ohgaito, R., Abe-Ouchi, A., and Emori, S.: Efficiently constraining climate sensitivity with paleoclimate simulations, SOLA, 1, 181-184, 2005.

Arnold Jr., C. and Dey, C.: Observing-systems simulation experiments: Past, present, and future, B. Am. Meteorol. Soc, 67, 687695, 1986.

Berger, A.: A simple algorithm to compute long term variations of daily or monthly insolation, Tech. Rep. 18, Universitè Catholique de Louvain, Belgium, 1978.

Bigelow, N., Brubaker, L., Edwards, M., et al.: Climate change and Arctic ecosystems: 1. Vegetation changes north of $55 \mathrm{~N}$ between the last glacial maximum, mid-Holocene, and present, J. Geophys. Res, 108, 8170, doi:10.1029/2002JD002558, 2003.

Braconnot, P., Otto-Bliesner, B., Harrison, S., Joussaume, S., Peterchmitt, J.-Y., Abe-Ouchi, A., Crucifix, M., Driesschaert, E., Fichefet, Th., Hewitt, C. D., Kageyama, M., Kitoh, A., Lainé, A., Loutre, M.-F., Marti, O., Merkel, U., Ramstein, G., Valdes, P., Weber, S. L., Yu, Y., and Zhao, Y.: Results of PMIP2 coupled simulations of the Mid-Holocene and Last Glacial Maximum Part 1: experiments and large-scale features, Clim. Past, 3, 261277, 2007, http://www.clim-past.net/3/261/2007/.

Braconnot, P., Otto-Bliesner, B., Harrison, S., Joussaume, S., Peterchmitt, J.-Y., Abe-Ouchi, A., Crucifix, M., Driesschaert, E., Fichefet, Th., Hewitt, C. D., Kageyama, M., Kitoh, A., Loutre, M.-F., Marti, O., Merkel, U., Ramstein, G., Valdes, P., Weber, L., Yu, Y., and Zhao, Y.: Results of PMIP2 coupled simulations of the Mid-Holocene and Last Glacial Maximum - Part 2: feedbacks with emphasis on the location of the ITCZ and mid- and high latitudes heat budget, Clim. Past, 3, 279-296, 2007, http://www.clim-past.net/3/279/2007/.

Collins, M., Booth, B., Harris, G., Murphy, J., Sexton, D., and Webb, M.: Towards quantifying uncertainty in transient climate change, Clim. Dynam., 27, 127-147, 2006.

Crucifix, M.: Does the Last Glacial Maximum constrain climate sensitivity?, Geophys. Res. Lett., 33, L18701, doi:10.1029/ 2006GL027137, 2006.

Hargreaves, J. C., Abe-Ouchi, A., and Annan, J. D.: Linking glacial and future climates through an ensemble of GCM simulations, Clim. Past, 3, 77-87, 2007, http://www.clim-past.net/3/77/2007/.

Jolly, D., Harrison, S., Damnati, B., and Bonnefille, R.: Simulated climate and biomes of Africa during the late quaternary comparison with pollen and lake status data, Quaternary Sci. Rev., 17, 629-657, 1998. 
Joussaume, S. and Braconnot, P.: Sensitivity of paleoclimate simulation results to season definitions, J. Geophys. Res., 102, 19431956, 1997.

Joussaume, S., Taylor, K., Bracconot, P., et al.: Monsoon changes for 6000 years ago: results of 18 simulations from the Paleoclimate Modeling Intercomparison Project (PMIP), Geophys. Res. Lett., 26, 859-862, 1999.

Knutti, R., Meehl, G., Allen, M., and Stainforth, D.: Constraining climate sensitivity from the seasonal cycle in surface temperature, J. Climate, 19, 4224-4233, 2006.

Meehl, G. A., Stocker, T. F., Collins, W. D., et al.: Global Climate Projections, in: Climate Change 2007: The physical science basis. Contribution of the Working Group I to the Fourth Assessment Report of the Intergovernmental Panel on Climate Change, chap. 10, Cambridge University Press, Cambridge, United Kingdom and New York, NY, USA, 2007.

Mitchell, J.: Greenhouse warming: Is the Mid-Holocene a good analogue?, J. Climate, 3, 1177-1192, 1990.

Murphy, J. M., Sexton, D. M. H., Barnett, D. N., Jones, G. S., Webb, M. J., Collins, M., and Stainforth, D. A.: Quantification of modelling uncertainties in a large ensemble of climate change simulations, Nature, 430, 768-772, 2004.

Ohgaito, R. and Abe-Ouchi, A.: The role of ocean thermodynamics and dynamics in Asian summer monsoon changes during the mid-Holocene, Clim. Dynam., 29, 39-50, 2007.

O'ishi, R. and Abe-Ouchi, A.: Influence of dynamic vegetation on climate change arising from increasing CO2, Clim. Dynam., 33(5), 645-663, doi:10.1007/s00382-009-0611-y, 2009.
Russell, G., Miller, J., and Tsang, L.: Seasonal oceanic heat transports computed from an atmospheric model, Dynam. Atmos. Oceans., 9, 253-271, 1985.

Schneider von Deimling, T., Held, H., Ganopolski, A., and Rahmstorf, S.: Climate sensitivity estimated from ensemble simulations of glacial climate, Clim. Dynam., 27, 149-163, 2006.

Solomon, S., Qin, D., Manning, M., Chen, Z., et al.: Climate change 2007: The physical science basis. Contribution of the Working Group I to the Fourth Assessment Report of the Intergovernmental Panel on Climate Change, 2007.

Tarasov, P., Guiot, J., Cheddadi, R., et al.: Climate in northern Eurasia 6000 years ago reconstructed from pollen data, Earth Planet Sc. Lett., 171, 635-645, 1999.

Tsushima, Y. and Manabe, S.: Influence of cloud-feedback on annual variation of global mean surface temperature, J. Geophys. Res., 106, 22635-22646, 2001.

Whetton, P., Macadam, I., Bathols, J., and O'Grady, J.: Assessment of the use of current climate patterns to evaluate regional enhanced greenhouse response patterns of climate models, Geophys. Res. Lett., 34, L14 701, doi:10.1029/2007GL030025, 2007.

Yokohata, T., Webb, M., Collins, M., Williams, K. D., Yoshimori, M., Hargreaves, J. C., and Annan, J. D.: Structural similarities and differences in climate responses to $\mathrm{CO}_{2}$ increase between two perturbed physics ensembles by general circulation models, J. Climate, in press, 2009. 